\section{Fixed Drug Eruption Due to Lorazepam}

Agulló-García $\mathrm{A}^{1,2}$, Garcés Sotillos $\mathrm{M}^{1,2}$, Colás Sanz $\mathrm{C}^{1,2}$

${ }^{1}$ Allergy Department. University Hospital Lozano Blesa of Zaragoza, Zaragoza, Spain

${ }^{2}$ Instituto de Investigación Sanitaria Aragón (IIS Aragón), Spain

J Investig Allergol Clin Immunol 2018; Vol. 28(3): 185-186 doi: 10.18176/jiaci.0225

Key words: Adverse drug reaction. Fixed drug eruption. Benzodiazepines. Lorazepam. Case report.

Palabras clave: Reacción adversa medicamentosa. Exantema fijo medicamentoso. Benzodiacepinas. Lorazepam. Caso clínico.

Lorazepam belongs to the highly potent benzodiazepine family, of which it shares the 5 intrinsic properties: anxiolytic, amnesic, sedative and hypnotic, anticonvulsive, and muscle relaxant. Although allergic reactions to benzodiazepines are rare, delayed hypersensitivity reactions have been reported [1], including fixed drug eruption (FDE) due to lormetazepam [2]. We report a case of lorazepam-induced FDE.

A 68-year-old man was referred to our department to rule out drug allergy. He had a history of arterial hypertension, hypercholesterolemia, hyperuricemia, nonallergic rhinitis, bladder carcinoma, nephrectomy, and ureterectomy. He was receiving long-term treatment with amlodipine, olmesartan, allopurinol, statins, and tamsulosin.

The patient had developed cutaneous pruritus and macular lesions on the trunk and limbs during hospitalization after bladder surgery; these were diagnosed as urticaria and treated with parenteral corticosteroids and antihistamines. The lesions lasted for several days and healed with residual hyperpigmentation. At that time, they were thought to have been caused by amoxicillin-clavulanic acid and metamizole, which had been administered for several days before surgery. Once the patient had been discharged, he presented the same kind of lesions at the same sites 8 hours after taking a lorazepam tablet to treat insomnia. The patient also reported taking a lorazepam tablet while in hospital.

Since the first suspected diagnosis was FDE, patch tests were performed with the Spanish Contact Dermatitis and Skin Allergy Research Group (GEIDAC) standard battery and the drugs involved (amoxicillin-clavulanic 10\% pet, metamizole $10 \%$ pet, and lorazepam $30 \%$ pet) at the affected sites, with negative readings at 48 and 96 hours. Skin prick tests and intradermal tests subsequently carried out with metamizole and B-lactams yielded negative results. Controlled oral challenge tests with amoxicillin-clavulanic acid and metamizole also yielded negative results. Finally, a controlled oral challenge test performed with lorazepam $(0.5 \mathrm{mg}$, repeated 1 hour later) was positive: 30 minutes after the cumulative dose of $1 \mathrm{mg}$, the patient developed pruritus with macular erythematous lesions on the palms and hypothenar eminences. The lesions progressed during the

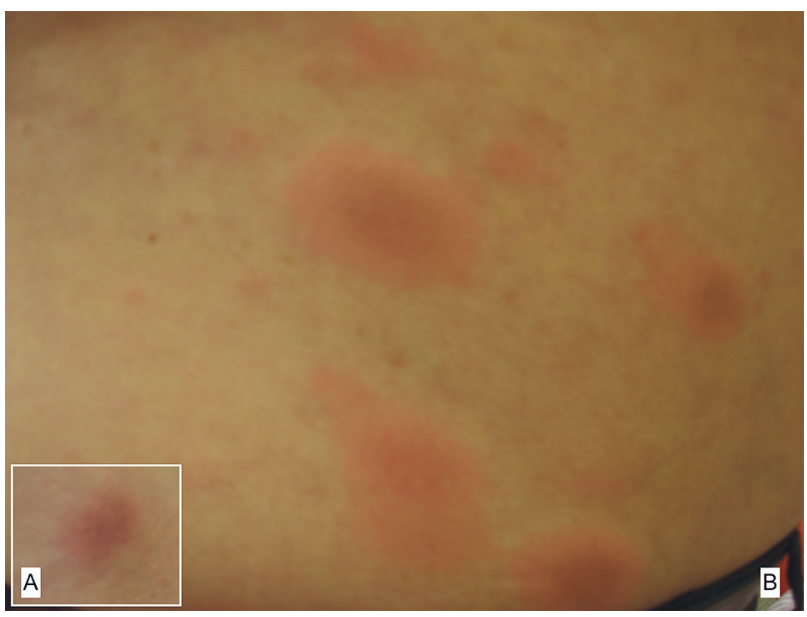

Figure. Fixed drug eruption lesions on the left arm $(A)$ and trunk $(B)$ 48 hours after a challenge test with an oral dose $(1 \mathrm{mg})$ of lorazepam.

following 48 hours and increased in number on the trunk and limbs (Figure), with subsequent appearance of vesicles on the mucosa of the hard palate. Peripheral eosinophilia $(10 \%)$ was also observed, and transaminases were not elevated. The patient was successfully treated with oral corticosteroids and antihistamines. His condition resolved within 15 days. On the basis of these findings, the study was extended using patch tests with a benzodiazepine series (lorazepam, midazolam, diazepam, bromazepam, zolpidem, and triazolam; $30 \%$ in pet) at the site of the residual lesion. However, the results were negative. To prevent further reactions, the patient was advised to avoid benzodiazepines. Previous studies have shown no cross-reactivity between tetrazepam and other benzodiazepines (bromazepam, diazepam, and midazolam) with patch testing and oral challenge $[1,3]$. However, we did not perform a controlled oral challenge with other benzodiazepines because of the risk involved and the lack of references for crossreactivity when testing lorazepam.

FDE is a delayed cutaneous hypersensitivity reaction characterized by recurrent well-defined lesions at the same location each time the culprit drug is taken. Mucous membranes can also be affected. FDE appears within minutes to several hours after intake and has been associated with many agents, the most common being nonsteroidal anti-inflammatory drugs [4,5], antibiotics [6], anticonvulsants, paracetamol, and antimalarial drugs [7]. However, to our knowledge, FDE due to lorazepam has not been previously reported. Sensitization occurs more readily in patients receiving the causative drugs intermittently than in those receiving them continuously [8], as is the case of benzodiazepines. While most reactions are limited to characteristic hyperpigmented lesions, some may progress to multiple or bullous lesions with subsequent administrations [9]; hence the need for early identification of the culprit drug. Topical provocation with patch testing must be performed at the sites of previous lesions, as the results depend on the activation of intraepidermal $\mathrm{CD} 8^{+}$memory $\mathrm{T}$ cells at these sites [10]. While topical provocation tests are safer, the false-negative rate is high; therefore, systemic challenge tests are the gold standard for diagnosis [7]. A short challenge may 
induce more severe reactions than a daily increase in doses, although we expected to obtain a negative result because there were no previously described cases.

In conclusion, we describe a case of multiple FDE due to lorazepam, a previously unreported causative agent of FDE.

\section{Funding}

The authors declare that no funding was received for the present study.

\section{Conflicts of Interest}

The authors declare that they have no conflicts of interest.

\section{References}

1. Del Pozo MD, Blasco A, Lobera T. Tetrazepam allergy. Allergy. 1999;54:1224-32.

2. Jafferany $M$, Haroon TS. Fixed drug eruption with lormetazepam (Noctamid). Dermatologica. 1988;177(6):386.

3. Laffond E, Dávila I, Moreno E, Morán M, Otero MJ, Sancho P, et al. Sensibilización a benzodiacepinas. Alergol Inmunol Clin. 2001;16(5):313-6.

4. Pérez-Calderón R, Gonzalo-Garijo MA, Pérez-Rangel I, SánchezVega S, Zambonino MA. Fixed Drug Eruption Due to Nabumetone in a Patient With Previous Fixed Drug Eruptions Due to Naproxen. J Invest Allergol Clin Immunol. 2011;21(2):153-4.

5. Ozdemir SK, Erkekol FO, Aydin O, Celik GE, Misirligil Z. Fixed Drug Eruption Due to Meloxicam. J Invest Allergol Clin Immunol. 2011;21(5):419-20.

6. Santosa A, Teo BW, Shek LP. Fixed Drug Eruption Caused by Piperacillin-Tazobactam. J Invest Allergol Clin Immunol. 2013;23(2):132-3.

7. Fernández FJ, López M, Barasona MJ, Cabañas MR, Rodríguez F. Manifestaciones clínicas por órganos y sistemas de las reacciones de hipersensibilidad inducidas por fármacos. Reacciones cutáneas graves. In: Dávila IJ, Jaúregui I, Olaguibel JM, Zubeldia JM, editors. Tratado de Alergología. SEAIC. Madrid: Ergon. 2016;1419-22.

8. Shiohara T. Fixed drug eruption: pathogenesis and diagnostic tests. Curr Opin Allergy Clin Immunol. 2009;9(4):316-21.

9. Sehgal VN, Srivastava G. Fixed drug eruption (FDE): changing scenario of incriminating drugs. Int I Dermatol. 2006:45(8):897-908.

10. Shiohara T, Mizukawa Y. Fixed drug eruption: a disease mediated by self-inflicted responses of intraepidermal T cells. Eur J Dermatol. 2007;17(3):201-8.

Manuscript received October 23, 2017; accepted for publication January 3, 2018.

Ana Agulló García

Servicio de Alergia Hospital Clínico Universitario Lozano Blesa Avda. San Juan Bosco 15 50009 Zaragoza, Spain

E-mail: aagullog@gmail.com 